OPEN ACCESS

Edited by:

Xian-Tao Zeng,

Wuhan University, China

Reviewed by:

Sandra Donnini,

University of Siena, Italy

Xin Liu,

Capital Medical University, China

*Correspondence:

Po-Ren Hsueh

hsporen@ntu.edu.tw

Wen-Chien Ko

winston3415@gmail.com

Specialty section:

This article was submitted to Translational Pharmacology,

a section of the journal

Frontiers in Pharmacology

Received: 19 July 2020

Accepted: 12 October 2020

Published: 17 November 2020

Citation:

Chen P-L, Lee N-Y, Cia C-T, Ko W-C,

Hsueh P-R (2020) A Review of

Treatment of Coronavirus Disease

2019 (COVID-19): Therapeutic

Repurposing and Unmet

Clinical Needs.

Front. Pharmacol. 11:584956.

doi: 10.3389/fphar.2020.584956

\section{A Review of Treatment of Coronavirus Disease 2019 (COVID-19): Therapeutic Repurposing and Unmet Clinical Needs}

\author{
Po-Lin Chen ${ }^{1,2,3}$, Nan-Yao Lee ${ }^{1,2}$, Cong-Tat Cia ${ }^{1,2}$, Wen-Chien Ko ${ }^{1,2 *}$ and Po-Ren Hsueh ${ }^{4 *}$ \\ ${ }^{1}$ Department of Internal Medicine, National Cheng Kung University Hospital, College of Medicine, National Cheng Kung University, \\ Tainan, Taiwan, ${ }^{2}$ Infection Control Center, National Cheng Kung University Hospital, College of Medicine, National Cheng Kung \\ University, Tainan, Taiwan, ${ }^{3}$ Department of Microbiology and Immunology, College of Medicine, National Cheng Kung University, \\ Tainan, Taiwan, ${ }^{4}$ Departments of Laboratory Medicine and Internal Medicine, National Taiwan University Hospital, National \\ Taiwan University College of Medicine, Taipei, Taiwan
}

For the initial phase of pandemic of coronavirus disease 2019 (COVID-19), repurposing drugs that in vitro inhibit severe acute respiratory syndrome coronavirus-2 (SARS-CoV-2) have been attempted with overlooked or overestimated efficacy owing to limited clinical evidence. Most early clinical trials have the defects of study design, small sample size, nonrandomized design, or different timings of treatment initiation. However, well-designed studies on asymptomatic or mild, or pediatric cases of COVID-19 are scarce and desperately needed to meet the clinical need. However, a trend could be observed based on current clinical evidence. Remdesivir and favipiravir may shorten the recovery time; lopinavir/ritonavir does not demonstrate treatment efficacy in severe patients. Triple therapy of ribavirin, lopinavir, and interferon $\beta-1 b$ showed early viral negative conversion, and the major effect may be related to interferon. Some small sample-size studies showed that interleukin-6 inhibitors may demonstrate clinical improvement; non-critical patients may benefit from convalescent plasma infusion in small sample-size studies; and the role of hydroxychloroquine or chloroquine in the treatment and prophylaxis of COVID-19 remains unclear. Combination therapy of traditional Chinese medicine with antiviral agents (ex. interferon, lopinavir, or arbidol) may alleviate inflammation in severe COVID-19 patients based on small sample-sized observational studies and experts' opinion. Most of the published studies included severe or critical patients with COVID-19. Combination therapy of antiviral agents and immune-modulating drugs is reasonable especially for those critical COVID-19 patients with cytokine release syndrome. Drugs to blunt cytokine release might not benefit for patients in the early stage with mild disease or the late stage with critical illness. Traditional Chinese medicine with antiviral effects on SARS-CoV-2 and immunemodulation is widely used for COVID-19 patients in China, and is worthy of further studies. In this review, we aim to highlight the available therapeutic options for COVID-19 based on current clinical evidence and encourage clinical trials specific for children and for patients with mild disease or at the early stage of COVID-19.

Keywords: COVID-19, SARS-CoV-2, treatment, anti-viral agents, interleukin-6 inhibitors, convalescent plasma 


\section{INTRODUCTION}

Severe acute respiratory syndrome coronavirus-2 (SARS-CoV-2) is a fresh linage of $\beta$-coronavirus, which is closely to bat SARSrelated coronavirus genetically (Chakraborty et al., 2020a). Since the outbreak of severe acute respiratory syndrome coronavirus-2 (SARS-CoV-2) in China toward the end of 2019, 32,110,656 cases were reported worldwide, and the virus caused 980,031 deaths, accounting for $3.05 \%$ of the infected population as of September 25, 2020 (World Health Organization, 2020). To date, no effective vaccines and promising antiviral agents for SARS-CoV-2 have been developed, and the currently available drugs are still under investigation. Therefore, many critically ill patients are treated with off-label antiviral drugs. Many drugs in emergency use are based on in vitro evidence or expert opinions. The clinical spectrum of COVID-19 ranges from asymptomatic carrier status or mild respiratory disease to severe pneumonia (Lai et al., 2020). COVID-19 tends to affect older patients with underlying medical conditions severely (Lai et al., 2020). In critical patients, lymphopenia, exhausted lymphocytes, and immune system activation due to concurrent cytokine release syndrome result in severe tissue damage (Cao, 2020b). Medications modulating inflammation may play a therapeutic role at this stage of disease. The publication of studies on COVID19 has been fast tracked. Notably, two articles on the use of hydroxychloroquine or chloroquine for COVID-19 in the New England Journal Medicine and Lancet were retracted owing to suspicious data sources (Mehra et al., 2020a; Mehra et al., 2020b).

As no specific therapy is available for SARS-CoV-2, the proposed therapy is based on the previous experience from SARS or Middle East Respiratory Syndrome (MERS) coronavirus. These therapeutic molecules, for example viral methyltransferase inhibitors, nitazoxanide, protease inhibitors (such as lopinavir/ritonavir), interferon, therapeutic peptides, RNA synthesis inhibitors (such as ribavirin, flavirapivir, and remdesivir), anti-inflammatory drugs, and traditional Chinese drugs are not designed specifically against SARS-CoV-2 (Chakraborty et al., 2020c), and some of them are preclinical drugs, not used in humans yet.

Most drugs currently used for COVID-19 are approved antiviral agents or antibodies against diseases other than COVID-19. The conceptual antiviral mechanisms for these drugs are summarized in Figure 1. Supporting evidence from well-designed clinical trials are limited, and there is a knowledge gap between clinical settings and sound scientific evidence. It is too early to conclude which drugs are effective against SARSCoV-2, because most studies were conducted urgently with limited number of patients with severe disease. For example, several trials on convalescent plasma (CP) include those with limited cases, non-randomized-controlled design, and targeting patients who needed extracorporeal membrane oxygenation support.

Theoretically, therapy with effective antiviral agents in the early phase of COVID-19 may gain greater benefits. Agents with anti-inflammatory characteristics may benefit critical COVID-19 patients who have features of cytokine release syndrome in addition to administration of antiviral drugs. Therefore, both disease severity and timing of therapy initiation would affect the final clinical or virological outcomes.

In the early period of COVID-19 outbreak, although most patients had moderate or severe COVID-19, they received experimental drugs only when their clinical condition deteriorated. Clinical data of treatment in asymptomatic cases or patients with mild COVID-19 are lacking. Although children were believed to be less susceptible to SAR-CoV-2, critical COVID-19 diseases have been reported in children (Dong et al., 2020). Further studies to fill the knowledge gap regarding therapy for severe COVID-19 in children are warranted.

Before effective antiviral drugs for COVID-19 are available, current treatment options will come from repurposing drugs. Thus, in this review we aim to highlight potential therapeutic strategies from the viewpoints of clinicians based on updated clinical evidences, and provide a basis for future researches of effective antiviral therapies. In the future, the development of new drugs and vaccines relies on multidisciplinary cooperation among structural biologists, chemists, and medical doctors. A knowledge gap of pharmacotherapy for COVID-19 is expected to be filled up, if updated information can be shared among global research institutes (Chakraborty et al., 2020d).

\section{REMDESIVIR}

Remdesivir, an RNA polymerase inhibitor, is a monophosphate prodrug that metabolizes to an active $\mathrm{C}$-adenosine nucleoside triphosphate analog and shows activity against RNA viruses, such as Coronaviridae and Flaviviridae (Siegel et al., 2017). Triphosphate form of remdesivir is a substrate for RNAdependent RNA polymerase complexes in coronaviruses and blocks viral RNA synthesis. Detailed mechanisms of remdesivir in inhibiting RNA polymerase is discussed in a review article by Saha et al. (2020a). It shows excellent in vitro activity against several coronaviruses, including SARS-CoV-2 with $\mathrm{EC}_{50}$ and $\mathrm{EC}_{90}$ values of 0.77 and $1.76 \mu \mathrm{M}$, respectively. Remdesivir is considered a potential therapy for COVID-19 in the beginning of outbreak (Al-Tawfiq et al., 2020; Wang M. et al., 2020). Holshue et al. reported the first case of COVID-19 treated with remdesivir in the United States; the patient's condition improved one day after initiation of remdesivir (Holshue et al., 2020). However, it is unclear whether the use of remdesivir resulted in this improvement. After that, remdesivir was compassionately used in 53 cases, of which 68\% showed improvement in oxygen support, $47 \%$ were discharged, and 13\% died (Grein et al., 2020).

During February-March 2020, the first randomized, placebocontrolled trial of remdesivir in China showed no virological benefits or clinical effect in reducing the recovery time and deaths compared with the placebo group. Moreover, it caused several adverse effects leading to early termination of the trial (Wang Y. et al., 2020). Other clinical trials of remdesivir are ongoing; preliminary data from an international multicenter, placebocontrolled double-blind randomized trial suggest that remdesivir is effective in reducing the recovery time from 15 to 11 days in hospitalized patients (Beigel et al., 2020). On April 


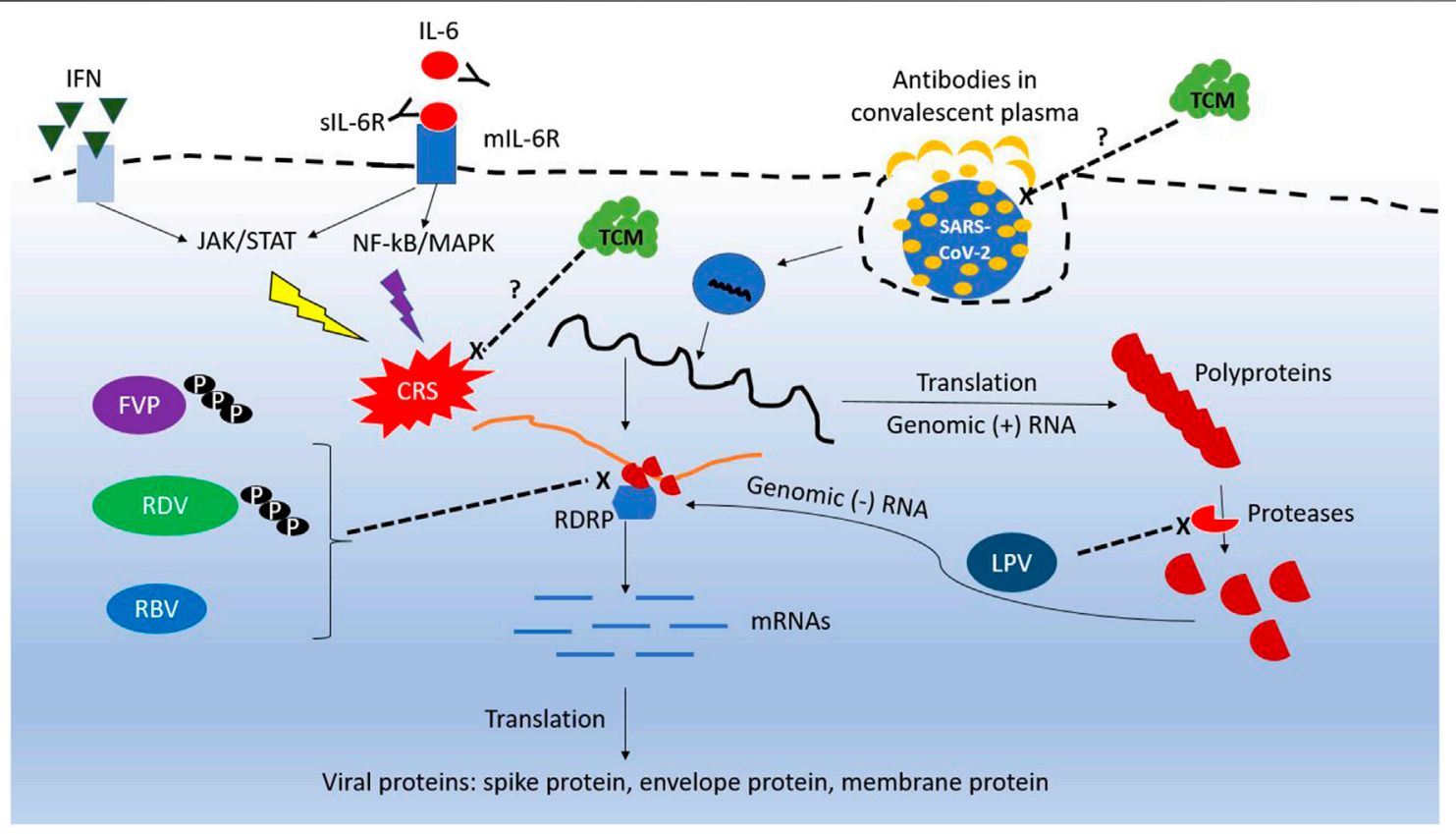

FIGURE 1 | Conceptual diagram of the mechanism for repurposing antiviral agents against SARS-CoV-2. RDV, remdesivir; FVP, favipiravir; RBV, ribavirin; IFN, interferon; sIL-6R, soluble IL-6 receptor; mIL-6R, membrane IL-6 receptor; TCM, traditional Chinese medicine.

29, 2020, based on the Adaptive COVID-19 Treatment Trial, the National Institute of Allergy and Infectious Diseases in the United States announced that remdesivir was better than placebo in reducing recovery time in hospitalized patients with advanced COVID-19 and lung involvement (National Institute of Allergy and Infectious Diseases, 2020). Currently, remdesivir is being tested as a specific treatment for COVID-19 and has been authorized for emergency use in people with severe symptoms in the United States (Food and Drug Administration, 2020c).

The dosage regimen of remdesivir under investigation is a single $200 \mathrm{mg}$ loading dose, followed by $100 \mathrm{mg}$ daily infusion. Remdesivir demonstrated linear pharmacokinetics within this dose range and an intracellular half-life of more than $35 \mathrm{~h}$ (Sanders et al., 2020). Dose adjustment for patients with impaired hepatic or kidney function is not recommended. However, remdesivir therapy is not recommended in patients with an estimated glomerular filtration rate less than $30 \mathrm{ml} / \mathrm{min}$ (Sanders et al., 2020). Adverse effects, including gastrointestinal and hepatic (elevated transaminase levels) dysfunction, and infusion site reactions were reported to be associated with remdesivir therapy (Grein et al., 2020; Mehta et al., 2020). In a study without placebo, prolonged courses of 10-days remdesivir therapy did not show a significant difference from 5 -days courses in patients with severe COVID-19 (oxygen saturation $\leq 94 \%$ in ambient air) not requiring mechanical ventilation (Goldman et al., 2020).

\section{FAVIPIRAVIR}

Favipiravir, an RNA polymerase inhibitor, is a prodrug of a purine nucleotide that inhibits viral replication (Sanders et al.,
2020), and it demonstrated activity against SARSCoV-2 with a high $\mathrm{EC}_{50}$ of $61.88 \mu \mathrm{M} / \mathrm{L}$ (Wang M. et al., 2020). Various dosing regimens have been proposed based on the type of infection indication (Sanders et al., 2020); a loading dose of 2,400-3,000 mg every $12 \mathrm{~h}$ (two doses) has been considered for the treatment of COVID-19, followed by a maintenance dose of 1,200-1800 mg every $12 \mathrm{~h}$ (Mentre et al., 2015; Sanders et al., 2020). Favipiravir demonstrates a tolerable safety profile in terms of total and serious adverse effects compared with other drugs used for short-term treatment (Pepperrell et al., 2020). Adverse effects of favipiravir, namely hyperuricemia, teratogenicity, and QTc prolongation have not been adequately studied despite its longterm and widespread use against COVID-19 (Pepperrell et al., 2020). However, there is limited clinical experience with favipiravir for COVID-19 treatment (Li J. et al., 2020; Sanders et al., 2020).

In February 2020, the use of favipiravir in the experimental treatment of COVID-19 was investigated in China. In a prospective, randomized, multicenter study, favipiravir (1,600 mg every $12 \mathrm{~h} /$ first day followed by $600 \mathrm{mg}$ every $12 \mathrm{~h} /$ day, $\mathrm{n}=120)$ was compared with umifenovir (200 mg every $8 \mathrm{~h} /$ day, $\mathrm{n}=120$ ) for the treatment of moderate and severe COVID19 infections for 10 days (Chen et al., 2020). On day 7, differences in clinical recovery were observed in patients with moderate infections (71.4\% in favipiravir arm and 55.9\% in umifenovir arm, $p=0.019$ ). Favipiravir significantly improved the resolution time of pyrexia and cough. However, there were no significant differences between patients with mild/moderate disease and severe/critical disease in the subgroup analysis. The other trials are planned in over 40 countries (Consumer News and Business Channel, 2020). 


\section{LOPINAVIR/RITONAVIR}

Lopinavir, an inhibitor of aspartate protease of human immunodeficiency virus (HIV), has been used in the treatment of HIV infection for a long time. Ritonavir can increase the concentration of lopinavir by inhibiting cytochrome P450. Lopinavir inhibits the action of protease $3 \mathrm{CL}^{\text {pro }}$ in $\mathrm{HIV}$ through C2-symmetric pocket, which is absent in coronavirus (Li and De Clercq 2020; Sheahan et al., 2020). Therefore, the inhibitory effect of lopinavir on SARS-CoV-2 is uncertain. In early May 2020, there was only one randomized controlled trial of lopinavir-ritonavir (LPVr), which was conducted in Wuhan, China (Cao et al., 2020a). In this study, 199 patients with COVID-19 pneumonia with oxygen saturation $\leq 94 \%$ in ambient air were included and randomly received LPVr 400/ $100 \mathrm{mg}$ or standard care. As no differences were observed in the time to clinical improvement, 28-days mortality rate, and detectable viral load at various time points between LPVr therapy and standard care, many clinicians disapproved LPVr. However, some experts showed interest in LPVr owing to its benefits in lowering overall mortality and reducing the risk of respiratory failure or acute respiratory distress syndrome (Dalerba et al., 2020; Kunz, 2020). Furthermore, this study included patients with COVID-19 at a median of 13 days after disease onset. Antiviral agents may not be effective, because hyper-inflammatory response rather than viral burden may be responsible for critical COVID-19 (Kunz 2020). They advocated that LPVr combination should be retained in the therapeutic guideline until ongoing well-controlled, randomized trials are completed. The other clinical trials had methodological defects such as small sample size and unblinding after review (Doward and Gbinigie, 2020). LPVr cannot be considered beneficial for patients with COVID-19 in terms of primary outcome (Doward and Gbinigie, 2020). As LPVr is a safe and widely available drug and the present data do not completely exclude its therapeutic role in the early onset of COVID-19 (for example, LPVr is prescribed for moderate cases within 7-10 days after symptom onset), further trials designed for such clinical settings are warranted.

\section{Ribavirin and Interferon}

Ribavirin, a guanosine analog which has distinct antiviral mechanisms, including both indirect (inosine monophosphate dehydrogenase inhibition and immunomodulatory effects) and direct mechanisms (interference with RNA capping, polymerase inhibition, and lethal mutagenesis) (Graci and Cameron, 2006). In vitro efficacy of ribavirin against SARS-CoV-2 viral strain WIV04 has been reported (Wang M. et al., 2020). In a singlecenter retrospective study conducted in Wuhan, China from January to February 2020, a total of 134 adults with severe COVID-19 were enrolled for analysis (Tong et al., 2020). Ribavirin therapy neither shortened the negative viral conversion time nor improved mortality rate. However, in a multicenter, prospective study conducted in Hong Kong, 127 patients were randomly assigned to the combination group (lopinavir $400 \mathrm{mg}$ and ritonavir $100 \mathrm{mg}$ every $12 \mathrm{~h}$, ribavirin $400 \mathrm{mg}$ every $12 \mathrm{~h}$, and three doses of eight million international units of interferon $\beta-1 b$ on alternate days for 14 days) or control group (lopinavir $400 \mathrm{mg}$ and ritonavir $100 \mathrm{mg}$ every $12 \mathrm{~h}$ for 14 days) at a ratio of 2:1 (Hung et al., 2020). The median number of days from symptom onset to the start of study treatment was 5 days. There was no difference of adverse events between the two groups. The results showed that the combination group had a significantly shorter median time from the initiation of combination treatment to negative nasopharyngeal swab (7 days; interquartile range [IQR] 5-11 days) than the control group (12 days; IQR 8-15 days; hazard ratio 4.37; 95\% confident interval [CI] 1.86-10.24]; $p=0 \cdot 001)$. This study suggested early prescription of combination antiviral therapy may shorten the duration of viral shedding and improve symptoms in patients with mild to moderate COVID-19 (Hung et al., 2020). However, clinical efficacy of such a combination regimen for severe COVID-19 remains obscure. Theoretically adverse effects of ribavirin, such as anemia, hypomagnesemia, and bradycardia, should always be reminded (Muller et al., 2007). However, neither ribavirin monotherapy nor concurrent use with other medications (i.e. interferon or lopinavir-ritonavir) for the patients with COVID-19 did not increase the incidence of the former adverse effects, in comparison with the controls in previous studies (Hung et al., 2020; Tong et al., 2020). To sum up, clinical efficacy and safety of ribavirin warrant more clinical investigations.

As interferons are important cytokines which may be involved in eliminating virus-infected cells (Samuel, 2001), the combination of interferon along with other antiviral agents would be a logic strategy. Interferon $\beta-1 b$ appears to be a key player of combination therapy based on the published data (Hung et al., 2020). Therefore, future trials with interferon-based combination regimens, including different doses, types of interferon, or concomitant drugs, are worthy to be conducted.

\section{CHLOROQUINE AND HYDROXYCHLOROQUINE}

Chloroquine has been used clinically for more than 70 years. It is an approved anti-malarial drug; it is also used for autoimmune diseases. In vitro studies showed that chloroquine was highly effective in controlling SARS-CoV-2 infection of host cells at the entry and post-entry stages (Wang M. et al., 2020). The antiviral mechanisms of chloroquine are multifaceted. It can prevent nanoparticle uptake by macrophages via inhibiting the expression of phosphatidylinositol-binding clathrin assembly protein and subsequent clathrin-mediated endocytosis. In addition, chloroquine can prevent acidification of lysosomes, thereby inhibiting their fusion with endocytic vesicles ( $\mathrm{Hu}$ et al., 2020).

A small open-label non-randomized trial conducted in France included 36 patients with COVID-19 (Gautret et al., 2020). The viral load was significantly lower in 20 cases treated with hydroxychloroquine sulfate $200 \mathrm{mg}$ three times a day for 10 days than in those without treatment on day 6 post inclusion $(70.0 \%$ vs. $12.5 \%, p=0.0001)$. Notably, six cases treated with hydroxychloroquine $(500 \mathrm{mg}$ on day 1 , followed 
by $250 \mathrm{mg}$ per day for the next 4 days) and azithromycin achieved $100 \%$ viral clearance rate on day 6 (Gautret et al., 2020). In this study, six patients withdrew from the treatment arm. The study endpoint was the viral load of throat swabs on day 6 after treatment initiation, which was not a clinical outcome. However, poor study method and reporting were the drawbacks of the study (Ferner and Aronson, 2020). Thus, the routine use of these drugs for COVID-19 was recently regarded as premature and potentially harmful owing to side effects such as fatal arrhythmia, drug eruption, and hepatitis. A study including 84 patients with COVID-19 receiving oral hydroxychloroquine (given at dose of $400 \mathrm{mg}$ twice on day 1, followed by $200 \mathrm{mg}$ twice daily for 5 days) and azithromycin (given at daily dose of $500 \mathrm{mg}$ for 5 days) was conducted in New York (Chorin et al., 2020). The included patients were followed up with electrocardiography (ECG) on an average of $4.3 \pm 1.7$ days. The results demonstrated prolongation of QTc from a baseline average of $435 \pm 24 \mathrm{~ms}$ to a maximal average value of $463 \pm 32 \mathrm{~ms}(p<$ $0.001)$. Notably, $11 \%$ of patients experienced severely prolonged QTc (>500 ms), which may cause arrhythmia and sudden cardiac death. Therefore, hydroxychloroquine should be used with caution, particularly in patients with co-morbidities and those who take QT-prolonging drugs. QTc assessment by ECG at the beginning and after therapy is warranted. The United States Food and Drug Administration (FDA) also cautions against the use of these drugs for COVID-19 outside the hospital setting or in a clinical trial owing to the risk of heart rhythm problems (Food and Drug Administration, 2020a).

\section{INTERLEUKIN-6 INHIBITORS}

Some patients with COVID-19 develop considerable inflammation associated with multiorgan failure requiring intensive care, and their severity and mortality of COVID-19 is associated with high levels of serum cytokines. Of note, high levels of pro-inflammatory cytokine and IL-6 were noted in severe COVID-19 patients (Giamarellos-Bourboulis et al., 2020; Qin et al., 2020; Wang C. et al., 2020). Such cytokine release syndrome was initiated through JAK-STAT or MAPK/ NF-кB-IL-6 pathway. Tocilizumab, a humanized monoclonal antibody, is able to bind both membrane bound receptors and soluble receptors for IL-6, and a potential drug for patients with severe COVID-19 (Saha et al., 2020b). Tocilizumab (TCZ), a humanized antibody targeting IL-6 receptor (IL-6R), has been licensed for the treatment of rheumatoid arthritis, juvenile idiopathic arthritis, giant cell arteritis, and chimeric antigen receptor T-cell therapy-induced cytokine release syndrome (Rubbert-Roth et al., 2018). Sarilumab, another IL-6R inhibitor for rheumatoid arthritis, and siltuximab, a chimeric monoclonal antibody against IL-6, are indicated for multicentric Castleman's disease (Boyce et al., 2018; van Rhee et al., 2018).

Several retrospective, non-randomized clinical studies reported favorable outcomes in patients treated with TCZ. A case-control study including 20 patients with COVID-19 receiving TCZ and 25 control patients reported fewer deaths and/or ICU admissions in the TCZ group (25\% vs.
$72 \%, p=0.002$ ) (Klopfenstein et al., 2020). TCZ has been associated with a lower risk of death in a before-after study of 85 non-intubated patients with COVID-19 having respiratory distress [hazard ratio of death: 0.035 (0.004-0.347, $p=0.004)$ ] (Capra et al., 2020). Another cohort study including 239 patients reported a higher than expected survival rate in severe patients treated with TCZ (Price et al., 2020). However, a retrospective cohort study including 65 patients (32 receiving TCZ) showed no significant difference in 28 -days mortality ( $15 \%$ vs. $33 \%, p=0.15)$ (Campochiaro et al., 2020). In summary, many case series demonstrated clinical improvement, radiological resolution, and decreased inflammation markers (Morena et al., 2020; Sciascia et al., 2020; Toniati et al., 2020; Xu et al., 2020). TCZ dosing in the reported studies ranged from 80 to $700 \mathrm{mg}$ per dose, usually $4-8 \mathrm{mg} / \mathrm{kg}$, in one or two doses. As TCZ is an immunosuppressant, its administration is occasionally associated with elevated liver enzymes, thrombocytopenia, and neutropenia (Morena et al., 2020). A substantial risk of bacteremia was reported when TCZ was administered in combination with methylprednisolone at a dose of $1 \mathrm{mg} / \mathrm{kg} /$ day (Giacobbe et al., 2020).

Other IL-6 inhibitors, such as siltuximab and sarilumab, have been reported as salvage therapy for COVID-19. Siltuximab $11 \mathrm{mg} / \mathrm{kg}$ (one or two doses) was administered in 21 patients with COVID-19 receiving either continuous positive airway pressure therapy or non-invasive ventilation, and $76 \%$ showed clinical improvement or stable condition (Gritti et al., 2020). Sarilumab at a dose of $400 \mathrm{mg}$, followed by $200 \mathrm{mg}$ twice in the subsequent days was administered in eight patients, and seven of them survived to discharge (Benucci et al., 2020).

As the current evidence supporting the use of IL-6 inhibitors for treating COVID-19 is weak, professional societies do not recommend its use outside clinical studies (Alhazzani et al., 2020; Bhimraj et al., 2020). Dozens of randomized, placebo-controlled trials of IL-6 inhibitors, such as clazakizumab, tociluzmab, sarilumab, or olokizumab, are ongoing (ClinicalTrials.gov, 2020), and were summarized and updated in Table 1 till September 09, 2020. Research outcomes for these studies are expected to fill the knowledge gap in the treatment efficacy of IL-6 inhibitors for patients with COVID-19.

\section{CONVALESCENT PLASMA}

Passive antibody administration for infectious diseases was introduced in the 1890 s and has been largely replaced by antimicrobial agents in the 20th century (Casadevall and Scharff, 1995). CP became a treatment option for severe viral diseases such as SARS, Middle East respiratory syndrome, influenza A H1N1/2009, and Ebola virus disease with variable results, because no specific treatment was available for these diseases (Cheng et al., 2005; Yeh et al., 2005; Hung et al., 2011; Mair-Jenkins et al., 2015; van Griensven et al., 2016).

Many physicians hope that CP transfusion would be effective in treating COVID-19. In addition, the FDA (United States) accepted applications for expanded access and single patient emergency use of CP (Food and Drug Administration, 2020b). 
TABLE 1 | Summary of current randomized, placebo-controlled clinical trials of IL-6 inhibitors for COVID-19.

\begin{tabular}{|c|c|c|c|c|c|c|c|}
\hline Drugs & Indication & Interventions & Multicenter & No. of cases & Phase of trail & Country & Registered no \\
\hline Clazakizumab & Life-threatening COVID-19 infection & Clazakizumab vs. placebo & No & 30 & $\|$ & United States & NCT04381052 \\
\hline Clazakizumab & Life-threatening COVID-19 infection & Clazakizumab 25 vs. 12.5 mg vs. placebo & No & 90 & $\|$ & United States & NCT04343989 \\
\hline Clazakizumab & Life-threatening COVID-19 infection & Clazakizumab vs. placebo & No & 30 & $\|$ & United States & NCT04363502 \\
\hline Tocilizumab & COVID-19 pneumonia & Tocilizumab vs. placebo & Yes & 379 & III & United States & NCT04372186 \\
\hline Tocilizumab & Moderate to severe COVID-19 pneumonia & Tocilizumab vs. placebo & Yes & 450 & III & United States & NCT04320615 \\
\hline Tocilizumab & Severe COVID-19 pneumonia & Remdesivir + tocilizumab vs. Remdesivir + placebo & Yes & 450 & III & United States & NCT04409262 \\
\hline Tocilizumab & COVID-19 disease & Tocilizumab vs. placebo & Yes & 100 & $\|$ & Switzerland & NCT04335071 \\
\hline Tocilizumab & SARS-CoV-2 infection and evidence of systemic inflammation & Tocilizumab vs. placebo & Yes & 243 & III & United States & NCT04356937 \\
\hline Sarilumab & Hospitalized COVID-19 patients & Sarilumab vs. placebo & Yes & 1912 & $\|/ /\| I I$ & United States & NCT04315298 \\
\hline Sarilumab & Severe or critical COVID-19 & Sarilumab dose 1 and dose 2 vs. placebo & Yes & 409 & III & Argentina & NCT04327388 \\
\hline Olokizumab & Severe COVID-19 & $\mathrm{RPH}-104^{\mathrm{a}}$ vs. Olokizumab vs. placebo & Yes & 372 & III & Russia & NCT04380519 \\
\hline
\end{tabular}

Data resource: ClinicalTials.gov, accessed on 9 September 2020.

${ }^{a} \mathrm{RPH}-104$, a novel heterodimeric fusion protein, capable of inhibition of human IL-1 beta/L-1F2 signaling pathway. 
TABLE 2 | Repurposing of potential candidate drugs for COVID-19.

\begin{tabular}{|c|c|c|c|c|c|c|}
\hline Therapy/Mechanism & Authors & Country & $\begin{array}{l}\text { Phase } \\
\text { of } \\
\text { trails }\end{array}$ & Methods & Primary outcome & Report findings \\
\hline \multirow[t]{2}{*}{$\begin{array}{l}\text { Remdesivir (RDV)/RNA polymerase } \\
\text { inhibitor }\end{array}$} & Wang et al & China & III & $\begin{array}{l}\text { Double-blinded RCT; RDV }(n=158) \text { vs. } \\
\text { placebo }(n=79)\end{array}$ & Clinical improvement up to 28 days & $\begin{array}{l}\text { RDV was not associated with a difference } \\
\text { in time to clinical improvement (hazard ratio } \\
1.23[95 \% \mathrm{Cl} 0.87-1.75] \text { ) }\end{array}$ \\
\hline & Beigel et al & $\begin{array}{l}\text { United } \\
\text { States }\end{array}$ & III & $\begin{array}{l}\text { Double-blinded; RDV }(n=538) \text { vs. placebo } \\
(n=521) \text {; hospitalized patients; favorable } \\
\text { outcome in preliminary report }\end{array}$ & Time to recovery & $\begin{array}{l}\text { Median recovery time: } 11 \text { days vs. } 15 \\
\text { days, recovery rate ratio, } 1.32 ; 95 \% \mathrm{Cl} \text {, } \\
1.12-1.55 ; p<0.001\end{array}$ \\
\hline $\begin{array}{l}\text { Lopinavir-ritonavir (LPV/r)/protease } \\
\text { inhibitor }\end{array}$ & Cao et al & China & $N / A$ & $\begin{array}{l}\text { Hospitalized patients with COVID-19 and } \\
\text { respiratory illness } ; \text {; open-label RCT; LPV/r } \\
(n=99) \text { vs. placebo }(n=100)\end{array}$ & Time to clinical improvement & $\begin{array}{l}\text { Modified intention-to-treat population }{ }^{\text {b: }} \\
\text { Median time to clinical improvement: } \\
15 \text { days vs. } 16 \text { days (hazard ratio, } 1.39 \text {; } \\
95 \% \mathrm{Cl}, 1.00-1.91 \text { ) }\end{array}$ \\
\hline Favipiravir (FPV)/RNA polymerase inhibitor & Chen et al & China & $N / A$ & $\begin{array}{l}\text { Adults with COVID-19 pneumonia; open- } \\
\text { label RCT; FPV ( } n=120,116 \text { accessed) vs. } \\
\text { UFV }(n=120)\end{array}$ & Clinical recovery rate on day 7 & $\begin{array}{l}\text { Clinical recovery rate on day } 7: 71.4 \% \text { vs. } \\
55.9 \% \text {; rate ratio }(95 \% \mathrm{Cl}): 0.16 \\
(0.03-0.28)\end{array}$ \\
\hline Ribavirin (RBV)/Guanosine analog & Tong et al & China & $N / A$ & $\begin{array}{l}\text { Adults with severe COVID-19; } \\
\text { retrospective study; RBV ( } n=44) \text { vs. none } \\
(n=71)\end{array}$ & Time to viral negative conversion & $12.8 \pm 4.1$ vs. $14.1 \pm 3.5$ days $(p=0.314)$ \\
\hline $\begin{array}{l}\text { Interferon (IFN) } \beta-1 b, R B V, L P V / r \text { I } \\
\text { Combination therapy }\end{array}$ & Hung et al & Hong Kong & $\|$ & $\begin{array}{l}\text { Adults with admitted COVID-19 patients; } \\
\text { open-label RCT }\end{array}$ & Time to viral negative conversion & $\begin{array}{l}7 \text { days vs. } 12 \text { days (hazard ratio, } 4.37 ; 95 \% \\
\mathrm{Cl}(1.85 \sim 10.24), p=0.0010)\end{array}$ \\
\hline \multirow[t]{2}{*}{$\begin{array}{l}\text { Chloroquine (CQ) and hydroxychloroquine } \\
\text { (HCQ) }\end{array}$} & Gautret et al & France & III & $\begin{array}{l}\text { Hospitalized patients with COVID-19 (age } \\
>12 \text { years) regardless of their clinical } \\
\text { status; open-label, non-RCT; HCQ } \pm \text { AZI ( } n \\
=26 \text { ) vs. none }(n=16)\end{array}$ & Viral clearance at day 6 & $70.0 \%$ vs. $12.5 \%, p=0.001$ \\
\hline & Mehra et al & Multinational & $N / A$ & $\begin{array}{l}\text { Hospitalized patients with COVID-19 } \\
\text { received treatment of interest within } 48 \mathrm{~h} \text {; } \\
\text { multinational registry analysis, CQ or } \\
\mathrm{HCQ} \pm \text { macrolide }(\mathrm{n}=14,888) \text { vs. none ( } \mathrm{n} \\
=81,144)\end{array}$ & $\begin{array}{l}\text { In-hospital mortality and de novo } \\
\text { ventricular arrhythmias }\end{array}$ & $\begin{array}{l}\text { Retracted owing to suspicious data } \\
\text { sources }\end{array}$ \\
\hline \multirow[t]{3}{*}{ Tocilizumab (TCZ)/Interleukin-6 inhibitors } & $\begin{array}{l}\text { Klopfenstein } \\
\text { et al }\end{array}$ & France & $\|$ & $\begin{array}{l}\text { Hospitalized adult patients with COVID-19; } \\
\text { TCZ }(n=20) \text { vs. control }(n=25)\end{array}$ & Death and/or ICU admission & $\begin{array}{l}\text { Patients with TCZ presented with severe } \\
\text { form; death and/or ICU admission: TCZ } \\
25 \% \text { vs. control } 72 \%, p=0.002\end{array}$ \\
\hline & $\begin{array}{l}\text { Campochiaro } \\
\text { et al }\end{array}$ & Italy & $\|$ & $\begin{array}{l}\text { Severe non-ICU adult patients with } \\
\text { COVID-19; TCZ }(n=32) \text { vs. control }(n=33)\end{array}$ & $\begin{array}{l}\text { Survival and clinical improvement at } \\
28 \text { days }\end{array}$ & $\begin{array}{l}\text { Clinical improvement: TCZ } 69 \% \text { vs. control } \\
61 \%, p=0.61 ; \text { mortality rate: TCZ } 15 \% \text { vs. } \\
\text { control } 33 \%, p=0.15\end{array}$ \\
\hline & Price et al & $\begin{array}{l}\text { United } \\
\text { States }\end{array}$ & $\|$ & $\begin{array}{l}\text { Hospitalized patients with COVID-19; } \\
\text { observational study; TCZ }(n=153) \text { vs. } \\
\text { control }(n=86)\end{array}$ & - & $\begin{array}{l}\text { TCZ-treated patients with similar survival } \\
\text { rates to non-severe patients }(83 \% \text { vs. } \\
91 \%, p=0.11)\end{array}$ \\
\hline $\begin{array}{l}\text { Convalescent plasma (CP)/Neutralizing } \\
\text { antibodies }\end{array}$ & Li et al & China & $\|$ & $\begin{array}{l}\text { Severe and life-threatening COVID-19; } \\
\text { RCT; CP }(n=52) \text { vs. standard treatment }(n \\
=51)\end{array}$ & Clinical improvement within 28 days & $\begin{array}{l}28 \text {-days clinical improvement: } \mathrm{CP} 51.9 \% \\
\text { vs. standard treatment } 43.1 \% \text {; hazard } \\
\text { ratio, } 1.40 \text { ( } 95 \% \mathrm{Cl}, 0.79-2.49), p=0.26 \text {. } \\
\text { Patients without life-threatening disease: } \\
28 \text {-days clinical improvement, hazard } \\
\text { ratio, } 2.15 \text { ( } 95 \% \mathrm{Cl}, 1.07-4.32) ; 72-\mathrm{h} \\
\text { negative conversion rate of viral nucleic } \\
\text { acid detection was higher in the } \mathrm{CP} \text { group } \\
\text { (87.2\% vs. } 37.5 \%, p<0.001) \\
\text { (Continued on following page) }\end{array}$ \\
\hline
\end{tabular}




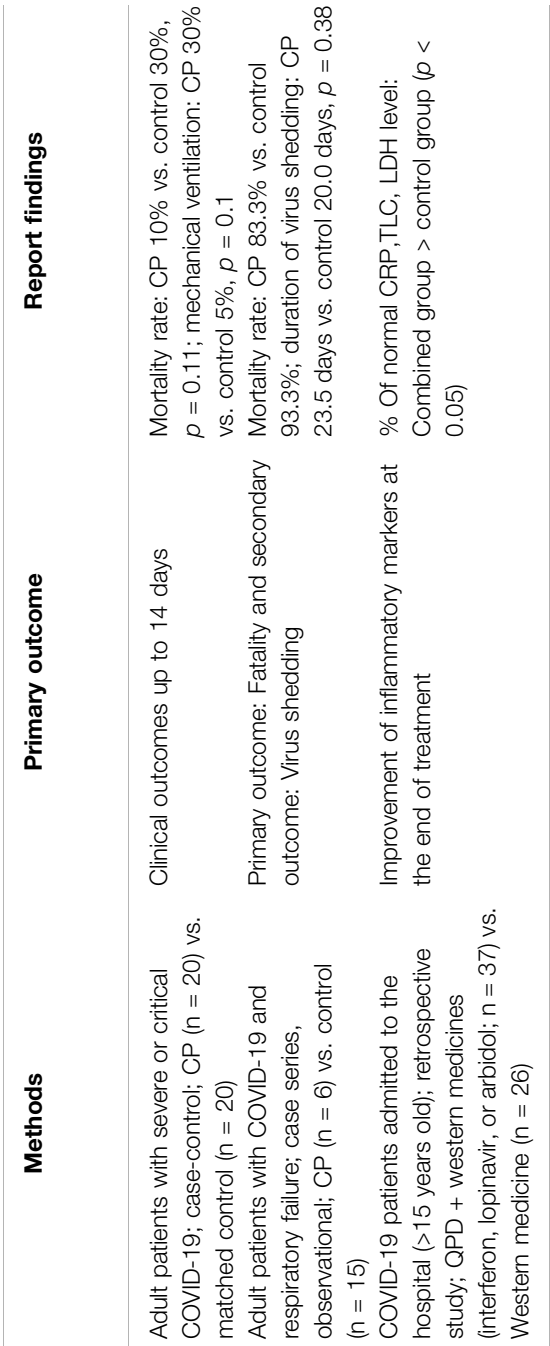

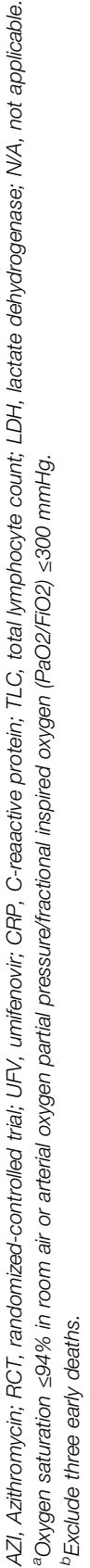

Up to $33 \%$ of patients who recovered from COVID-19 generated very low titers of SARS-CoV-2 neutralizing antibodies. Therefore, neutralizing antibody testing is highly recommended for CP donors (Robbiani et al., 2020; Wu et al., 2020).

A prematurely terminated, possibly underpowered, randomized controlled trial involving 103 patients with severe or life-threatening COVID-19 who received CP at a dose of $4-13 \mathrm{ml} / \mathrm{kg}$ showed no significant difference in the rate of clinical improvement within 28 days $(51.9 \%$ vs. $43.1 \%$, difference $8.8 \%$ [95\% CI: $-10.4-28.0 \%]$ ). In the subgroup analysis, only patients with life-threatening disease were more likely to improve after $\mathrm{CP}$ transfusion (hazard ratio, 2.15; 95\% CI, 1.07-4.32). The 72-h negative conversion rate of viral nucleic acid detection was higher in the CP group (87.2\% vs. $37.5 \%, p<0.001$ ) (Li L. et al., 2020).

Seven case series reported the treatment outcomes of $\mathrm{CP}$ in patients with COVID-19 with disease severity ranging from mild disease to severe respiratory failure on extracorporeal membrane oxygenation (Ahn et al., 2020; Duan et al., 2020; Pei et al., 2020; Salazar et al., 2020; Shen et al., 2020; Ye et al., 2020; Zhang B. et al., 2020). In these case series, clinical improvement, radiological resolution of pneumonia, and decreased viral load were observed in most patients; however, studies with comparable groups showed less promising results. One study reported a high fatality rate in both groups (5/6 in the $\mathrm{CP}$ group and 14/15 in the control group), and another study showed only slight improvement in oxygen and laboratory values (Hegerova et al., 2020; Zeng et al., 2020). The volume of CP in the above studies ranged from 200 to $600 \mathrm{ml}$ per time for one or two sessions. The safety of $\mathrm{CP}$ transfusion was supported by the initial analysis of 5,000 patients involved in the US FDA Expanded Access Program, which demonstrated serious adverse events in $0.5 \%$ of CP recipients (Joyner et al., 2020). More than 10 randomized controlled trials have been commenced to clarify the efficacy of $\mathrm{CP}$ in the treatment of COVID-19 (ClinicalTrials.gov, 2020).

\section{TRADITIONAL CHINESE MEDICINE}

In the early outbreak in China, no drugs approved for the treatment of COVID-19 were limited. Therefore, the China official guideline suggested traditional Chinese medicine (TCM) in combination with antiviral drugs for COVID-19 patients (Novel Coronavirus Pneumonia Diagnosis and Treatment Plan, Provisional 7th ed., 2020). In China, TCM wards were set up in the hospitals and some COVID-19 cases were treated accordingly. Of note, Qingfei Paidu Decoction (QPD) has been strongly recommended for confirmed cases in different categories in the official guidelines based on the practical clinical experiences by the China official guideline. QPD comprises 21 traditional Chinese medicines, which are expected to have protective effects for different organs, in addition to lung. Of the components in QPD, five are supposed to possess in vitro suppressive effects on SARS virus (Yu et al., 2012; Zhang D. H. et al., 2020). 
In a retrospective, one-center study conducted in Hubei Province, China between January and February 2020, 63 patients with COVID-19 treated with antiviral agents alone $(\mathrm{n}=26)$ and in combination with QPD $(\mathrm{n}=37)$ were analyzed (Xin et al., 2020). Antiviral agents used in this study included interferon, arbidol, or lopinavir. Before QPD treatment, the combination group had higher blood levels of C-reactive protein (CRP) and more pulmonary inflammation and clinical symptoms than the antiviral group. At the end of treatment, death rate, length of hospital stay, and improvement of pulmonary CT score were similar in both groups. Of note, CRP, creatine kinase, creatine kinase-myocardial band, lactate dehydrogenase, and blood urea nitrogen levels were improved only in the QPD therapy group (all $p<0.05$ ). Although QPD has both antiviral and anti-inflammatory potential, its precise treatment effect for COVID-19 needs to be clarified and therapeutic efficacy requires clinical validation through well-designed randomized-control studies.

\section{Vaccines in Development}

In addition to antiviral agents, the global use of COVID-19 vaccine is a promising strategy to end the current pandemic. Dozens of COVID-19 vaccines designed by different organizations are at different phases of clinical trials. Saha et al. summarized a total of 146 COVID-19 vaccines, including live-attenuated vaccine, inactivated or killed vaccine, subunit vaccine, and nucleic acid-based vaccine, engaged in clinical trials (Saha et al., 2020c), and the number of candidates will be increasing in the future. With the aid of immunoinformatics, scientists could select suitable peptide sequences which are potential B- or T-cell epitopes for the generation of epitopic vaccines against SARS-CoV-2 (Bhattacharya et al., 2020a; Bhattacharya et al., 2020b). Another example is the peptide vaccine against spike glycoprotein with molecular docking on toll-like receptor-5 (TLR5), which can evoke early innate immune response against COVID-19 (Chakraborty et al., 2020b). However, the efficacy of these candidate vaccines remains to be verified.

\section{CONCLUSION}

The COVID-19 pandemic is still severe, and most of the drugs currently available for COVID-19 are not designed specifically against SARS-CoV-2. The search for effective antiviral agents specific to SARS-CoV-2 is still ongoing. The potential drugs for COVID-19 are summarized in Table 2. Ideally, the inhibition of viral proliferation in early stage of COVID-19 can prevent

\section{REFERENCES}

Ahn, J. Y., Sohn, Y., Lee, S. H., Cho, Y., Hyun, J. H., Baek, Y. J., et al. (2020). Use of convalescent plasma therapy in two COVID-19 patients with acute respiratory distress syndrome in Korea. J. Korean Med. Sci. 35, e149. doi:10.3346/jkms.2020.35.e149

Al-Tawfiq, J. A., Al-Homoud, A. H., and Memish, Z. A. (2020). Remdesivir as a possible therapeutic option for the COVID-19. Travel. Med. Infect. Dis. 34, 101615. doi:10.1016/j.tmaid.2020.101615 subsequent severe complications. In contrast, critical cases of COVID-19 benefit from anti-inflammation therapy in conjunction with antiviral agents, as in late stage cytokine release syndrome is the main cause of multi-organ failure and even death. Clinical evidence suggests that remdesivir can shorten the recovery time of advanced COVID-19 pneumonia. However, the clinical efficacy and safety of other agents for emergency use is controversial owing to the limitations of study designs. IL-6 inhibitors, which alleviate severe inflammation induced by cytokine release after viral infection, may improve clinical outcome of critical cases of COVID-19. Several clinical trials of IL-6 inhibitors for severe COVID-19 patients are conducted. It is still too early to draw conclusions until more evidences from well-designed clinical trials are available. Traditional Chinese herbs are worthy of further investigations. However, the precise antiviral mechanisms of traditional Chinese medicines remain difficult to be explored, as the regimens often contain multiple components. In addition, their therapeutic efficacy needs concrete evaluations based on well-designed clinical studies. Although supporting evidences for other antiviral agents and convalescent plasma are less than those for remdesivir, the clinical application of the aforementioned therapies may still be considered in the real world setting for patients with severe COVID-19, if no contraindications are present, owing to the limited treatment choices.

In summary, COVID-19 vaccine is the most promising strategy to end the current pandemic in addition to anti-viral agents. Design of novel anti-viral agents which are specific for SARS-CoV-2 will provide more effective therapy for COVID-19 patients. Development of effective vaccines and anti-viral drugs both needs multidisciplinary cooperation. Before effective vaccines and antiviral drugs are available, therapy with repurposing drugs are still the mainstream. Drugs which suppress virus may benefit patients in the early phase of COVID-19. Agents with anti-inflammatory characteristics may benefit critical COVID-19 patients who have features of cytokine release syndrome in addition to administration of antiviral drugs. Traditional Chinese medicines may have advantages in aspects of immunomodulation and suppressing virus when administrating with other anti-viral agents.

\section{AUTHOR CONTRIBUTIONS}

PLC, NYL, and CTC reviewed and analyzed the data. PCC, NYL, CTC, WCK and PRH prepared the manuscript. PLC, NYL, CTC, WCK and PRH read and approved the final version of the manuscript.

Alhazzani, W., Møller, M. H., Arabi, Y. M., Loeb, M., Gong, M. N., Fan, E., et al. (2020). Surviving Sepsis Campaign: guidelines on the management of critically ill adults with coronavirus disease 2019 (COVID-19). Intensive Care Med. 46, 854-887. doi:10.1007/s00134020-06022-5

Beigel, J. H., Tomashek, K. M., Dodd, L. E., Mehta, A. K., Zingman, B. S., Kalil, A. C., et al. (2020). Remdesivir for the treatment of COVID-19 preliminary report. N. Engl. J. Med. [Epub ahead of print]. doi:10.1056/ NEJMoa2007764 
Benucci, M., Giannasi, G., Cecchini, P., Gobbi, F. L., Damiani, A., Grossi, V., et al. (2020). COVID-19 pneumonia treated with Sarilumab: a clinical series of eight patients. J. Med. Virol. 92, 2368-2370. doi:10.1002/jmv.26062

Bhattacharya, M., Sharma, A. R., Patra, P., Ghosh, P., Sharma, G., Patra, B. C., et al. (2020a). Development of epitope-based peptide vaccine against novel coronavirus 2019 (SARS-COV-2): immunoinformatics approach. J. Med. Virol. 92, 618-631. doi:10.1002/jmv.25736

Bhattacharya, M., Sharma, A. R., Patra, P., Ghosh, P., Sharma, G., Patra, B. C., et al. (2020b). A SARS-CoV-2 vaccine candidate: in-silico cloning and validation. Inform. Med. Unlocked 20, 100394. doi:10.1016/j.imu.2020.100394.

Bhimraj, A., Morgan, R. L., Shumaker, A. H., Lavergne, V., Baden, L., Cheng, V. C., et al. (2020). Infectious Diseases Society of America guidelines on the treatment and management of patients with COVID-19. Clin. Infect. Dis. [in press]. doi:10.1093/cid/ciaa478

Boyce, E. G., Rogan, E. L., Vyas, D., Prasad, N., and Mai, Y. (2018). Sarilumab: review of a second IL-6 receptor antagonist indicated for the treatment of rheumatoid arthritis. Ann. Pharmacother. 52, 780-791. doi:10.1177/ 1060028018761599

Campochiaro, C., Della-Torre, E., Cavalli, G., De Luca, G., Ripa, M., Boffini, N., et al. (2020). Efficacy and safety of tocilizumab in severe COVID-19 patients: a single-centre retrospective cohort study. Eur. J. Intern. Med. 76, 43-49. doi:10. 1016/j.jim.2020.05.021

Cao, B., Wang, Y., Wen, D., Liu, W., Wang, J., Fan, G., et al. (2020a). A trial of lopinavir-ritonavir in adults hospitalized with severe COVID-19. N. Engl. J. Med. 382, 1787-1799. doi:10.1056/NEJMoa2001282

Cao, X. (2020b). COVID-19: immunopathology and its implications for therapy. Nat. Rev. Immunol. 20, 269-270. doi:10.1038/s41577-020-0308-3

Capra, R., De Rossi, N., Mattioli, F., Romanelli, G., Scarpazza, C., Sormani, M. P., et al. (2020). Impact of low dose tocilizumab on mortality rate in patients with COVID-19 related pneumonia. Eur. J. Intern. Med. 76, 31-35. doi:10.1016/j. ejim.2020.05.009

Casadevall, A., and Scharff, M. D. (1995). Return to the past: the case for antibodybased therapies in infectious diseases. Clin. Infect. Dis. 21, 150-161. doi:10. 1093/clinids/21.1.150

Chakraborty, C., Sharma, A. J., Bhattacharya, M., Sharma, G., and Lee, S. S. (2020a). The 2019 novel coronavirus disease (COVID-19) pandemic: a zoonotic prospective. Asian Pac J Trop Med 13, 242-246. doi:10.4103/ $1995-7645.281613$

Chakraborty, C., Sharma, A. R., Bhattacharya, M., Sharma, G., Lee, S. S., and Agoramoorthy, G. (2020b). Consider TLR5 for new therapeutic development against COVID-19. J. Med. Virol. [Epub ahead of print]. doi:10.1002/jmv.25997

Chakraborty, C., Sharma, A. R., Sharma, G., Bhattacharya, M., and Lee, S. S. (2020c). SARS-CoV-2 causing pneumonia-associated respiratory disorder (COVID-19): diagnostic and proposed therapeutic options. Eur. Rev. Med. Pharmacol. Sci. 24, 4016-4026. doi:10.26355/eurrev_202004_20871

Chakraborty, C., Sharma, A. R., Sharma, G., Bhattacharya, M., Saha, R. P., and Lee, S. S. (2020d). Extensive partnership, collaboration, and teamwork is required to stop the COVID-19 outbreak. Arch. Med. Res. S0188-4409 (20), 30849-3. doi:10.1016/j.arcmed.2020.05.021

Chen, C., Zhang, Y., Huang, J., Yin, P., Cheng, Z., Wu, J., et al. (2020). Favipiravir versus arbidol for COVID-19: a randomized clinical trial. medRxiv [Preprint]. Available at: https://doi.org/10.1101/2020.03.17.20037432 (Accessed July 5, 2020).

Cheng, Y., Wong, R., Soo, Y. O., Wong, W. S., Lee, C. K., Ng, M. H., et al. (2005). Use of convalescent plasma therapy in SARS patients in Hong Kong. Eur. J. Clin. Microbiol. Infect. Dis. 24, 44-46. doi:10.1007/s10096-004-1271-9

Chorin, E., Dai, M., Shulman, E., Wadhwani, L., Bar-Cohen, R., Barbhaiya, C., et al. (2020). The QT interval in patients with COVID-19 treated with hydroxychloroquine and azithromycin. Nat. Med. 26, 808-809. doi:10.1038/ s41591-020-0888-2

ClinicalsTrial.gov (2020). Available at: https://clinicaltrials.gov. (Accessed July 4, 2020).

Consumer News and Business Channel (2020). Available at: https://www.cnbc.com/ 2020/05/04/fujifilms-flu-drug-favipiravir-sent-to-43-nations-for-covid-19-trials. html. (Accessed July 4, 2020).

Dalerba, P., Levin, B., and Thompson, J. L. 2020. A trial of lopinavir-ritonavir in COVID-19. N. Engl. J. Med. 382, e68. doi:10.1056/NEJMc2008043
Dong, Y., Mo, X., Hu, Y., Qi, X., Jiang, F., Jiang, Z., et al. (2020). Epidemiology of COVID-19 among children in China. Pediatrics 145, e20200702. doi:10.1542/ peds.2020-0702

Doward, J., and Gbinigie, K. (2020). Lopinavir/ritonavir: a rapid reviewof effectiveness in COVID-19. Available at: https://www.cebm.net/covid-19/ lopinavir-ritonavir-a-rapid-review-of-the-evidence-for-effectiveness-intreating-covid. (Accessed July 4, 2020).

Duan, K., Liu, B., Li, C., Zhang, H., Yu, T., Qu, J., et al. (2020). Effectiveness of convalescent plasma therapy in severe COVID-19 patients. Proc. Natl. Acad. Sci. U.S.A. 117, 9490-9496. doi:10.1073/pnas.2004168117

Ferner, R. E., and Aronson, J. K. (2020). Chloroquine and hydroxychloroquine in covid-19. BMJ 369, m1432. doi:10.1136/bmj.m1432

Food and Drug Administration (2020a). FDA cautions against use of hydroxychloroquine or chloroquine for COVID-19 outside of the hospital setting or a clinical trial due to risk of heart rhythm problems. Available at: https://www.fda.gov/drugs/drug-safety-and-availability/fda-cautions-againstuse-hydroxychloroquine-or-chloroquine-covid-19-outside-hospital-setting-or (Accessed July 4, 2020).

Food and Drug Administration (2020b). Recommendations for investigational COVID-19 convalescent plasma. Available at: https://www.fda.gov/vaccinesblood-biologics/investigational-new-drug-ind-or-device-exemption-ideprocess-cber/recommendations-investigational-covid-19-convalescent-plasma (Accessed July 5, 2020).

Food and Drug Administration (2020c). Remdesivir EUA letter of authorization (FDA).1 May 2020. Available at: https://www.fda.gov/media/137564/download (Accessed July 4, 2020).

Gautret, P., Lagier, J. C., Parola, P., Hoang, V. T., Meddeb, L., Mailhe, M., et al. (2020). Hydroxychloroquine and azithromycin as a treatment of COVID-19: results of an open-label non-randomized clinical trial. Int. J. Antimicrob. Agents 20, 105949. doi:10.1016/j.ijantimicag.2020.105949

Giacobbe, D. R., Battaglini, D., Ball, L., Brunetti, I., Bruzzone, B., Codda, G., et al. (2020). Bloodstream infections in critically ill patients with COVID-19. Eur. J. Clin. Invest. 14, e13319. doi:10.1111/eci.13319

Giamarellos-Bourboulis, E. J., Netea, M. G., Rovina, N., Akinosoglou, K., Antoniadou, A., Antonakos, N., et al. (2020). Complex immune dysregulation in COVID-19 patients with severe respiratory failure. Cell Host. Microbe. 27, 992-1000.e3. doi:10.1016/j.chom.2020.04.009

Goldman, J. D., Lye, D. C. B., Hui, D. S., Marks, K. M., Bruno, R., Montejano, R., et al. (2020). Remdesivir for 5 or 10 days in patients with severe COVID-19. N. Engl. J. Med. [Epub ahead of print]. doi:10.1056/NEJMoa2015301

Graci, J. D., and Cameron, C. E. (2006). Mechanisms of action of ribavirin against distinct viruses. Rev. Med. Virol. 16, 37-48. doi:10.1002/rmv.483.

Grein, J., Ohmagari, N., Shin, D., Diaz, G., Asperges, E., Castagna, A., et al. (2020). Compassionate use of remdesivir for patients with severe COVID-19. N. Engl. J. Med.; 382, 2327-2336. doi:10.1056/NEJMoa2007016

Gritti, G., Ripamonti, D., Riva, I., Landi, F., Alborghetti, L., Frigeni, M., et al. (2020). Use of siltuximab in patients with COVID-19 pneumonia requiring ventilatory support. medRxiv [Preprint]. Available at: https://doi.org/10.1101/ 2020040120048561 (Accessed June 20, 2020).

Hegerova, L., Gooley, T., Sweerus, K. A., Maree, C. L., Bailey, N., et al. (2020). Use of convalescent plasma in hospitalized patients with COVID-19 - case series. Blood 136, 759-762. doi:10.1182/blood.2020006964

Holshue, M. L., DeBolt, C., Lindquist, S., Lofy, K. H., Wiesman, J., Bruce, H., et al. (2020). First case of 2019 novel Coronavirus in the United States. N. Engl. J. Med. 382, 929-936. doi:10.1056/NEJMoa2001191

$\mathrm{Hu}, \mathrm{T}$. Y., Frieman, M., and Wolfram, J. (2020). Insights from nanomedicine into chloroquine efficacy against COVID-19. Nat. Nanotechnol. 15, 247-249. doi:10. 1038/s41565-020-0674-9

Hung, I. F., Lung, K. C., Tso, E. Y., Liu, R., Chung, T. W., Chu, M. Y., et al. (2020). Triple combination of interferon beta- $1 \mathrm{~b}$, lopinavir-ritonavir, and ribavirin in the treatment of patients admitted to hospital with COVID-19: an open-label, randomised, phase 2 trial. Lancet 395 (10238), 1695-1704. doi:10.1016/S01406736(20)31042-4.

Hung, I. F., To, K. K., Lee, C. K., Lee, K. L., Chan, K., Yan, W. W., et al. (2011). Convalescent plasma treatment reduced mortality in patients with severe pandemic influenza A (H1N1) 2009 virus infection. Clin. Infect. Dis. 15 (52), 447-456. doi:10.1093/cid/ciq106 
Joyner, M. J., Wright, R. S., Fairweather, D., Senefeld, J. W., Bruno, K. A., Klassen, S. A., et al. (2020). Early safety indicators of COVID-19 convalescent plasma in 5,000 patients. J. Clin. Invest. 130, 4791-4797. doi:10.1172/JCI140200

Klopfenstein, T., Zayet, S., Lohse, A., Balblanc, J. C., Badie, J., Royer, P. Y., et al. (2020). Tocilizumab therapy reduced intensive care unit admissions and/or mortality in COVID-19 patients. Med. Maladies Infect. 50, 397-400. doi:10. 1016/j.medmal.2020.05.001

Kunz, K. M. (2020). A trial of lopinavir-ritonavir in COVID-19. N. Engl. J. Med. 21, e68. doi:10.1056/NEJMc2008043

Lai, C. C., Liu, Y. H., Wang, C. Y., Wang, Y. H., Hsueh, S. C., Yen, M. Y., et al. (2020). Asymptomatic carrier state, acute respiratory disease, and pneumonia due to severe acute respiratory syndrome coronavirus 2 (SARS-CoV-2): facts and myths. J. Microbiol. Immunol. Infect. 53, 404-412. doi:10.1016/j.jmii.2020. 02.012

Li, G., and De Clercq, E. (2020). Therapeutic options for the 2019 novel coronavirus (2019-nCoV). Nat. Rev. Drug Discov. 19, 149-150. doi:10.1038/ d41573-020-00016-0

Li, J., Zhang, C., Wu, Z., Wang, G., and Zhao, H. (2020). The Mechanism and clinical outcome of patients with Corona virus disease 2019 whose nucleic acid test has changed from negative to positive, and the therapeutic efficacy of favipiravir: a structured summary of a study protocol for a randomised controlled trial. Trials 21, 488. doi:10.1186/s13063-020-04430-y

Li, L., Zhang, W., Hu, Y., Tong, X., Zheng, S., Yang, J., et al. (2020). Effect of convalescent plasma therapy on time to clinical improvement in patients with severe and life-threatening COVID-19: a randomized clinical trial. JAMA 324, 460-470. doi:10.1001/jama.2020.10044

Mair-Jenkins, J., Saavedra-Campos, M., Baillie, J. K., Cleary, P., Khaw, F. M., Lim, W. S., et al. (2015). The effectiveness of convalescent plasma and hyperimmune immunoglobulin for the treatment of severe acute respiratory infections of viral etiology: a systematic review and exploratory meta-analysis. J. Infect. Dis. 211, 80-90. doi:10.1093/infdis/jiu396

Mehra, M. R., Desai, S. S., Kuy, S., Henry, T. D., and Patel, A. N. (2020a). Retraction: cardiovascular disease, drug therapy, and mortality in Covid-19. N. Engl. J. Med. 382, 2582. doi:10.1056/NEJMc2021225

Mehra, M. R., Desai, S. S., Ruschitzka, F., and Patel, A. N. (2020b). RETRACTED: hydroxychloroquine or chloroquine with or without a macrolide for treatment of COVID-19: a multinational registry analysis. Lancet 395, 1820. doi:10.1016/ S0140-6736(20)31180-6

Mehta, N., Mazer-Amirshahi, M., Alkindi, N., and Pourmand, A. (2020). Pharmacotherapy in COVID-19; A narrative review for emergency providers. Am. J. Emerg. Med. 38, 1488-1493. doi:10.1016/j.ajem.2020.04.035

Mentre, F., Taburet, A. M., Guedj, J., Anglaret, X., Keita, S., de Lamballerie, X., et al. (2015). Dose regimen of favipiravir for Ebola virus disease. Lancet Infect. Dis. 15, 150-151. doi:10.1016/S1473-3099(14)71047-3

Morena, V., Milazzo, L., Oreni, L., Bestetti, G., Fossali, T., Bassoli, C., et al. (2020). Off-label use of tocilizumab for the treatment of SARS-CoV-2 pneumonia in Milan, Italy. Eur. J. Intern. Med. 76, 36-42. doi:10.1016/j.ejim.2020.05.011

Muller, M. P., Dresser, L., Raboud, J., McGeer, A., Rea, E., Richardson, S. E., et al. (2007). Adverse events associated with high-dose ribavirin: evidence from the Toronto outbreak of severe acute respiratory syndrome. Pharmocotherapy. 27, 494-503. doi:10.1592/phco.27.4.494.

National Institute of Allergy and Infectious Diseases (2020). NIH clinical trial shows remdesivir accelerates recovery from advanced COVID-19. (Press release on 29 April 2020). Available at: https://www.niaid.nih.gov/news-events/nih-clinicaltrial-shows-remdesivir-accelerates-recovery-advanced-covid-19. (Accessed July $5,2020)$.

Novel Coronavirus Pneumonia Diagnosis and Treatment Plan, Provisional 7th ed. (2020). English version. Available at: http://www.gov.cn/zhengce/zhengceku/ 2020-03/04/5486705/files/ae61004f930d47598711a0d4cbf874a9.pdf (Accessed September 27, 2020).

Pei, S., Yuan, X., Zhang, Z. Z., Yao, R. R., Xie, Y., Shen, M. M., et al. (2020). Convalescent plasma to treat COVID-19: Chinese strategy and experiences. medRxiv [Preprint]. Available at: https://doi.org/10.1101/2020.04.07.20056440 (Accessed July 7, 2020)

Pepperrell, T., Pilkington, V., Owen, A., Wang, J., and Hill, A. M. (2020). Review of safety and minimum pricing of nitazoxanide for potential treatment of COVID19. J. Virus Erad. 6, 52-60. doi:10.1016/S2055-6640(20)30017-0
Price, C. C., Altice, F. L., Shyr, Y., Koff, A., Pischel, L., Goshua, G., et al. (2020). Tocilizumab treatment for cytokine release syndrome in hospitalized COVID19 patients: survival and clinical outcomes. Chest 158, 1397-1408. doi:10.1016/j. chest.2020.06.006

Qin, C., Zhou, L., Hu, Z., Zhang, S., Yang, S., Tao, Y., et al. 2020. Dysregulation of immune response in patients with COVID-19 in Wuhan, China. Clin. Infect. Dis. 71, 762-768. doi:10.1093/cid/ciaa248

Robbiani, D. F., Gaebler, C., Muecksch, F., Lorenzi, J. C. C., Wang, Z., Cho, A., et al. (2020). Convergent antibody responses to SARS-CoV-2 in convalescent individuals. Nature 584, 437-442. doi:10.1038/s41586-020-2456-9

Rubbert-Roth, A., Furst, D. E., Nebesky, J. M., Jin, A., and Berber, E. (2018). A review of recent advances using tocilizumab in the treatment of rheumatic diseases. Rheumatol. Ther. 5, 21-42. doi:10.1007/s40744-018-0102-x

Saha, A., Sharma, A. R., Bhattacharya, M., Sharma, G., Lee, S. S., and Chakraborty, C. (2020a). Probable molecular mechanism of remdesivir for the treatment of COVID-19: need to know more. Arch. Med. Res. 51, 585-586. doi:10.1016/j. arcmed.2020.05.001.

Saha, A., Sharma, A. R., Bhattacharya, M., Sharma, G., Lee, S. S., and Chakraborty, C. (2020b). Tocilizumab: a therapeutic option for the treatment of cytokine storm syndrome in COVID-19. Arch. Med. Res. 51 (6), 595-597. doi:10.1016/j. arcmed.2020.05.009

Saha, R. P., Sharma, A. R., Singh, M. K., Samanta, S., Bhakta, S., Mandal, S., et al. (2020c). Repurposing drugs, ongoing vaccine, and new therapeutic development Initiatives against COVID-19. Front. Pharmacol. 11, 1258. doi:10.3389/fphar.2020.01258

Salazar, E., Perez, K. K., Ashraf, M., Chen, J., Castillo, B., Christensen, P. A., et al. (2020). Treatment of coronavirus disease 2019 (COVID-19) patients with convalescent plasma. Am. J. Pathol. 190, 1680-1690. doi:10.1016/j.ajpath. 2020.05.014

Samuel, C. E. (2001). Antiviral actions of interferons. Clin. Microbiol. Rev. 14, 778-809. doi:10.1128/CMR.14.4.778-809.2001

Sanders, J. M., Monogue, M. L., Jodlowski, T. Z., and Cutrell, J. B. (2020). Pharmacologic Treatments for coronavirus disease 2019 (COVID-19): a review. JAMA. 323, 1824-1836. doi:10.1001/jama.2020.6019

Sciascia, S., Apra, F., Baffa, A., Baldovino, S., Boaro, D., Boero, R., et al. (2020). Pilot prospective open, single-arm multicentre study on off-label use of tocilizumab in patients with severe COVID-19. Clin. Exp. Rheumatol. 38, 529-532.

Sheahan, T. P., Sims, A. C., Leist, S. R., Schafer, A., Won, J., Brown, A. J., et al. (2020). Comparative therapeutic efficacy of remdesivir and combination lopinavir, ritonavir, and interferon beta against MERS-CoV. Nat. Commun. 11, 222. doi:10.1038/s41467-019-13940-6

Shen, C., Wang, Z., Zhao, F., Yang, Y., Li, J., Yuan, J., et al. (2020). Treatment of 5 critically ill patients with COVID-19 with convalescent plasma. JAMA 323, 1582-1589. doi:10.1001/jama.2020.4783

Siegel, D., Hui, H. C., Doerffler, E., Clarke, M. O., Chun, K., Zhang, L., et al. (2017). Discovery and synthesis of a phosphoramidate prodrug of a pyrrolo[2,1-f] [triazin-4-amino] adenine c-nucleoside (GS-5734) for the treatment of Ebola and emerging viruses. J. Med. Chem. 60, 1648-1661. doi:10.1021/acs.jmedchem. $6 \mathrm{~b} 01594$

Tong, S., Su, Y., Yu, Y., Wu, C., Chen, J., Wang, S., et al. (2020). Ribavirin therapy for severe COVID-19: a retrospective cohort study. Int. J. Antimicrob. Agents. 56 (3), 106114. doi:10.1016/j.jjantimicag.2020.106114.

Toniati, P., Piva, S., Cattalini, M., Garrafa, E., Regola, F., Castelli, F., et al. (2020). Tocilizumab for the treatment of severe COVID-19 pneumonia with hyperinflammatory syndrome and acute respiratory failure: a single center study of 100 patients in Brescia, Italy. Autoimmun. Rev. 19, 102568. doi:10. 1016/j.autrev.2020.102568

van Griensven, J., Edwards, T., de Lamballerie, X., Semple, M. G., Gallian, P., Baize, S., et al. (2016). Evaluation of convalescent plasma for Ebola virus disease in Guinea. N. Engl. J. Med. 374, 33-42. doi:10.1056/NEJMoa1511812

van Rhee, F., Voorhees, P., Dispenzieri, A., Fossa, A., Srkalovic, G., Ide, M., et al. (2018). International, evidence-based consensus treatment guidelines for idiopathic multicentric Castleman disease. Blood 132, 2115-2124. doi:10. 1182/blood-2018-07-862334.

Wang, C., Fei, D., Li, X., Zhao, M., and Yu, K. (2020). IL-6 may be a good biomarker for earlier detection of COVID-19 progression. Intensive Care Med. 46, 1475-1476. doi:10.1007/s00134-020-06065-8 
Wang, M., Cao, R., Zhang, L., Yang, X., Liu, J., Xu, M., et al. (2020). Remdesivir and chloroquine effectively inhibit the recently emerged novel coronavirus (2019$\mathrm{nCoV})$ in vitro. Cell Res. 30, 269-271. doi:10.1038/s41422-020-0282-0

Wang, Y., Zhang, D., Du, G., Du, R., Zhao, J., Jin, Y., et al. (2020). Remdesivir in adults with severe COVID-19: a randomised, double-blind, placebo-controlled, multicentre trial. Lancet 395, 1569-1578. doi:10.1016/S0140-6736(20)31022-9

World Health Organization (2020). WHO coronavirus (COVID-19) dashboard. Available at: https://covid19.who.int/?gclid=Cj0KCQjwqfz6BRD8ARIsAIXQC f27seTSiDoxGUpIFdNnioLtqYOkzi38U9ZMZjW4psIw2s77TeCWHT8aAp5nEALw_ wcB (Accessed September 15, 2020).

Wu, F., Liu, M., Wang, Q., Chen, J., Xia, S., Ling, Y., et al. (2020). Neutralizing antibody responses to SARS-CoV-2 in a COVID-19 recovered patient cohort and their implications. medRxiv [Preprint]. Available at: https://doi.org/10. 1101/2020.03.30.20047365 (Accessed July 5, 2020).

Xin, S., Cheng, X., Zhu, B., Liao, X., Yang, F., Song, L., et al. (2020). Clinical retrospective study on the efficacy of Qingfei Paidu decoction combined with Western medicine for COVID-19 treatment. Biomed. Pharmacother. 129, 110500. doi:10.1016/j.biopha.2020.110500

Xu, X., Han, M., Li, T., Sun, W., Wang, D., Fu, B., et al. (2020). Effective treatment of severe COVID-19 patients with tocilizumab. Proc. Natl. Acad. Sci. U.S.A. 117, 10970-10975. doi:10.1073/pnas.2005615117

Ye, M., Fu, D., Ren, Y., Wang, F., Wang, D., Zhang, F., et al. 2020. Treatment with convalescent plasma for COVID-19 patients in Wuhan, China. J. Med. Virol. [in press]. doi:10.1002/jmv.25882

Yeh, K. M., Chiueh, T. S., Siu, L. K., Lin, J. C., Chan, P. K., Peng, M. Y., et al. (2005). Experience of using convalescent plasma for severe acute respiratory syndrome among healthcare workers in a Taiwan hospital. J. Antimicrob. Chemother. 56, 919-922. doi:10.1093/jac/dki346
Yu, M. S., Lee, J., Lee, J. M., Kim, Y., Chin, Y. W., Jee, J. G., et al. (2012) Identification of myricetin and scutellarein as novel chemical inhibitors of the SARS coronavirus helicase, nsP13. Bioorg. Med. Chem. Lett 12, 4049-4054. doi:10.1016/j.bmcl.2012.04.081.

Zeng, Q. L., Yu, Z. J., Gou, J. J., Li, G. M., Ma, S. H., Zhang, G. F., et al. (2020). Effect of Convalescent plasma therapy on viral shedding and survival in COVID-19 patients. J. Infect. Dis. 222, 38-43. doi:10.1093/ infdis/jiaa228

Zhang, B., Liu, S., Tan, T., Huang, W., Dong, Y., Chen, L., et al. (2020). Treatment with convalescent plasma for critically ill patients with severe acute respiratory syndrome coronavirus 2 infection. Chest 158, e9-e13. doi:10.1016/j.chest.2020. 03.039

Zhang, D. H., Wu, K. L., Zhang, X., Deng, S. Q., and Peng, B. (2020). In silico screening of Chinese herbal medicines with the potential to directly inhibit 2019 novel coronavirus. J Integr Med 18, 152-158. doi:10.1016/j.joim.2020. 02.005

Conflict of Interest: The authors declare that the research was conducted in the absence of any commercial or financial relationships that could be construed as a potential conflict of interest.

Copyright (c) 2020 Chen, Lee, Cia, Ko and Hsueh. This is an open-access article distributed under the terms of the Creative Commons Attribution License (CC BY). The use, distribution or reproduction in other forums is permitted, provided the original author(s) and the copyright owner(s) are credited and that the original publication in this journal is cited, in accordance with accepted academic practice. No use, distribution or reproduction is permitted which does not comply with these terms. 